\title{
ANÁLISE PLUVIOMÉTRICA NO ESTADO DO PARÁ: COMPARAÇÃO ENTRE DADOS OBTIDOS DE ESTAÇÕES PLUVIOMÉTRICAS E DO SATÉLITE GPCC
}

\author{
FERREIRA FILHO, David Figueiredo - davydferreira@gmail.com \\ Universidade Federal do Pará / UFPA
}

\author{
LIRA, Bruna Roberta Pereira - brunalira14@hotmail.com \\ Universidade Federal do Pará / UFPA
}

\author{
CRISPIM, Diêgo Lima - dlimacrispim@gmail.com \\ Universidade Federal do Pará / UFPA
PESSOA, Francisco Carlos Lira - fclpessoa@ufpa.br Universidade Federal do Pará / UFPA
FERNANDES, Lindemberg Lima - linlimfer@gmail.com Universidade Federal do Pará / UFPA

\begin{abstract}
RESUMO: O presente estudo teve como objetivo analisar o comportamento pluviométrico das médias mensais e anuais das precipitações pluviométricas obtidas de duas fontes de dados diferentes, HidroWeb (ANA) e do satélite meteorológico GPCC, para a série de dados, no período de 1986 a 2015 no estado do Pará. Com auxílio de ferramentas de Sistemas de Informações Geográficas (SIG) foi feito a interpolação de ambas as fontes de dados, pelo método de Krigagem, para médias mensais e anuais, justamente às suas comparações. Para avaliar o desempenho se utilizaram como métodos estatísticos os testes do coeficiente de correlação de Pearson ( $R$ ), coeficiente de determinação $\left(R^{2}\right)$, coeficiente de Nash-Sutcliffe (NASH), o Erro Quadrático Médio (MSE) e a Raiz do Erro Quadrático Médio (RMSE). Para ambos os dados se notaram uma semelhança na interpolação dos mesmos, e a espacialização da distribuição da precipitação média anual para o período através do método de interpolação, evidenciou que os maiores índices pluviométricos estão localizados no Nordeste Paraense, abrangendo áreas das mesorregiões do Marajó e da Região Metropolitana de Belém. Além disto, os resultados obtidos pelo GPCC e ANA, indicaram que os menores índices de precipitações foram observados na porção sudeste do estado. Os resultados obtidos para a distribuição da média mensal da precipitação do estado do Pará, indicaram comportamentos similares para sazonalidade, no qual se observou duas estações bem distintas ao longo dos anos, uma chuvosa e outra menos chuvosa. Logo, os meses com maiores registros de precipitação foi fevereiro, março e abril, enquanto os meses menos chuvosos foi agosto e setembro. Os resultados dos testes estatísticos, com base em suas classificações, evidenciaram que em alguns meses os dados são fortes entre si, e outros são moderados. Assim, o comportamento pluviométrico é não-homogêneo e os conjuntos de dados apresentaram similaridades, confirmando a boa consistência entre as diferentes fontes de dados, demonstrando e contribuindo como subsídio para a gestão e planejamento dos recursos hídricos no estado e fortalecendo ainda mais a ideia da utilização de satélites meteorológicos em hidrologia.
\end{abstract}

PALAVRAS-ChAVE: Comportamento pluviométrico, Dinâmica espacial e temporal, Krigagem, Espacialização de Chuvas.

PLUVIOMETRIC ANALYSIS IN THE STATE OF PARÁ: COMPARISON BETWEEN DATA
OBTAINED FROM PLUVIOMETRIC STATIONS AND SATELLITE GPCC

ABSTRACT: This study aimed at analyzing the rainfall behavior of monthly and annual rainfall averages obtained from two different data sources, HidroWeb (ANA) and the meteorological satellite GPCC, for the data series from 1986 to 2015 in the state of Pará. 
With the help of Geographic Information Systems (GIS) tools, both data sources were interpolated, using the Krigagem method, to monthly and annual averages, exactly to their comparisons. To evaluate the performance, Pearson's correlation coefficient $(R)$, determination coefficient $\left(\mathrm{R}^{2}\right)$, Nash-Sutcliffe's coefficient (NASH), Mean Square Error (MSE) and Mean Square Error Root (RMSE) tests were used as statistical methods. For both data a similarity in their interpolation was noticed, and the spatialization of the distribution of the annual mean rainfall for the period through the interpolation method, evidenced that the largest pluviometric indexes are located in the Northeast Para, covering areas of the mesoregions of Marajó and the Metropolitan Region of Belém. Furthermore, the results obtained by GPCC and ANA indicated that the lowest rainfall indices were observed in the southeastern portion of the state. The results obtained for the distribution of the monthly average rainfall of the state of Pará, indicated similar behavior for seasonality, in which two very distinct seasons were observed throughout the years, one rainy and the other less rainy. Therefore, the months with the highest rainfall were February, March, and April, while the least rainy months were August and September. The results of the statistical tests, based on their ratings, showed that in some months the data are strong among themselves, and others are moderate. Thus, the pluviometric behavior is non-homogenic and the data sets presented similarities, confirming the good consistency between the different data sources, demonstrating and contributing as subsidy to the management and planning of water resources in the state and further strengthening the idea of using meteorological satellites in hydrology.

KEYWORDS: Pluviometric behavior, Spatial and temporal dynamics, Kriging, Rain Spatialization.

ANÁLISIS PLUVIOMÉTRICO EN EL ESTADO DE PARÁ: COMPARACIÓN ENTRE LOS DATOS OBTENIDOS DE LAS ESTACIONES PLUVIOMÉTRICAS Y SATELITE GPCC

RESUMEN: Este estudio tuvo como objetivo analizar el comportamiento de las precipitaciones de los promedios mensuales y anuales obtenidos de dos fuentes de datos diferentes, HidroWeb (ANA) y el satélite meteorológico GPCC, para las series de datos de 1986 a 2015 en el estado de Pará. Con la ayuda de las herramientas de los Sistemas de Información Geográfica (SIG), ambas fuentes de datos se interpolaron, utilizando el método Krigagem, a promedios mensuales y anuales, exactamente a sus comparaciones. Para evaluar el rendimiento, se utilizaron como métodos estadísticos las pruebas del coeficiente de correlación de Pearson $(R)$, el coeficiente de determinación $\left(R^{2}\right)$, el coeficiente de Nash-Sutcliffe (NASH), el error cuadrático medio (MSE) y la raíz del error cuadrático medio (RMSE). En ambos datos se observó una similitud en su interpolación, y la espacialización de la distribución de la precipitación media anual para el período mediante el método de interpolación, evidenció que los mayores índices pluviométricos se encuentran en el Nordeste de Pará, abarcando áreas de las mesoregiones de Marajó y la Región Metropolitana de Belém. Además, los resultados obtenidos por la GPCC y la ANA indicaron que los índices de precipitaciones más bajos se observaron en la parte sudoriental del estado. Los resultados obtenidos para la distribución de las precipitaciones medias mensuales del estado de Pará, indicaron un comportamiento similar para la estacionalidad, en la que se observaron dos estaciones muy distintas a lo largo de los años, una lluviosa y otra menos lluviosa. Por lo tanto, los meses de mayor precipitación fueron febrero, marzo y abril, mientras que los meses menos lluviosos fueron agosto y septiembre. Los resultados de las pruebas estadísticas, basados en sus calificaciones, mostraron que en algunos meses los datos son fuertes entre sí, y en otros son moderados. Así pues, el comportamiento pluviométrico no es homogéneo y los conjuntos de datos presentan similitudes, lo que confirma la buena coherencia entre las diferentes fuentes de datos, demuestra y contribuye como subsidio a la gestión y planificación de los recursos hídricos del Estado y refuerza aún más la idea de utilizar los satélites meteorológicos en la hidrología como un subsidio para la gestión y planificación de los recursos hídricos en el estado.

PALABRAS CLAVE: Comportamiento pluviométrico, Dinámica espacial y temporal, Kriging, Espacialización de lluvias. 


\section{INTRODUÇÃO}

A precipitação é um dos principais elementos climáticos na região tropical (OLIVEIRA JÚNIOR et al., 2014), pois, além de influenciar no comportamento de outros elementos atmosféricos, tais como, umidade relativa do ar e temperatura do ar, a precipitação é a que melhor caracteriza as variabilidades climáticas (SOUSA et al., 2015).

Essa variável climatológica é importante para diversas atividades humanas, seja elas econômica, social e/ou ambiental, podendo-se destacar no setor agrícola (CARMELLO; SANT'ANNA NETO, 2015), hidroelétrico (ISHIHARA et al., 2014), industrial (TEIXEIRA et al., 2016), entre outros, além disso, é o principal componente para o abastecimento dos corpos hídricos, que tem importância para os ecossistemas e o desenvolvimento de um país.

Uma das grandes dificuldades para a realização de pesquisas pluviométricas consistem na rede de monitoramento (WANDERLEY et al., 2012), pois, as estações meteorológicas apresentam diversos problemas, devido estarem localizadas em áreas de difícil acesso, locais inadequados, erros nas coletas de dados e relatos de problemas técnicos (CRISPIM et al., 2019), bem como possuem período de observação curto, bastante falhas e baixa densidade de estações (LIMBERGER; SILVA, 2018).

Pesquisas com dados de satélite e radar tem se destacado, por causa da democratização dos dados meteorológicos por meio de processos de aquisição destes, através de downloads de diversas plataformas de grandes centros mundiais de pesquisa (DEE et al., 2016). Outro ponto, é que as técnicas de geoprocessamento estão sendo muito utilizadas para diversas finalidades, assim como na avaliação da variabilidade pluviométrica, pois, auxiliam no planejamento e na gestão dos recursos hídricos (CIRINO et al., 2019).

De acordo com Lucas et al. (2009), permitem a compreensão da oferta hídrica, podendo assegurar o uso sustentável da água para diversas atividades, como, abastecimento público, irrigação, indústria, aquicultura, entre outros. Assim, a geoestatística é a ferramenta que vem auxiliando na estimativa e espacialização da precipitação. As grades de dados interpolados ajudam a resolver um dos principais entraves das pesquisas, que são as dificuldades de obtenção de dados, seja por insuficiência nas séries históricas, por falhas de medições e poucas densidades de estações (LIMBERGER; SILVA, 2018).

Segundo Hrachowitz et al. (2013) o uso da precipitação estimada por satélite como dado de entrada para modelos hidrológicos pode ser uma alternativa para fornecer previsões de precipitação em unidades com poucos ou quase nenhum dado, facilitando o gerenciamento dos recursos hídricos e estudos acerca da previsão de impactos ambientais. Por este motivo que dados das grades regulares sofrem reanálises, obtidos através de sensoriamento remoto ou de dados de previsão de tempo/climáticos obtidos por modelagem numérica (FASULLO, 2012).

Os dados provenientes de modelagem são constituídos por matrizes de dados referentes ao instante inicial usado em cada integração matemática com o objetivo de elaborar previsões de tempo. Antes de serem repassados, os dados observados em superfície e altitude passam por métodos de consistências 
e interpolações, parte da inicialização (HOLTON, 1973), e por fim são executados de forma a gerar as previsões de tempo e fornecidos ao público (DEE et al., 2016).

Os dados de reanálises são frutos do conjunto de dados produzidos por centros de pesquisas meteorológicas, tais como a Administração Nacional Oceânica e Atmosférica (NOAA) no EUA, o Centro Nacional de Pesquisas Atmosféricas (CNPA), a Administração Nacional da Aeronáutica e Espaço (NASA), o Centro Europeu de Previsões Meteorológicas a Médio Prazo (CEPMMP) (FASULLO, 2012).

Cada centro tem seu modelo numérico para aplicar as previsões climáticas, por isso os conjuntos de reanálises têm diferenças entre si, levando a estudos de comparação dos conjuntos distintos de reanálises (HARADA et al., 2016; TRENBERTH et al., 2011). Entre estes, o conjunto de dados de precipitação do Centro de Climatologia de Precipitação Global (GPCC), considerado como referência, pois, consiste na combinação e incorporação de bancos de dados.

No Brasil, a Lei n. ${ }^{\circ} 9.433$ de 1997 institui a Política Nacional de Recursos Hídricos (PNRS) e cria o Sistema Nacional de Gerenciamento de Recursos (BRASIL, 1997). Sendo, o pluviômetro é o tipo de medição de precipitação mais utilizado pela Rede Hidrométrica Nacional por meio da Agência Nacional de Águas (ANA), o órgão responsável pela regulação dos recursos hídricos, monitoramento hidrometeorológico e disponibilidade das séries históricas e informações através do Sistema de Informações Hidrológicas (HidroWeb), ferramenta para análise pluviométrica.

O estado do Pará é caracterizado por uma ampla variabilidade pluviométrica, decorrente da atuação de diferentes sistemas atmosféricos atuantes (MENEZES et al., 2015). De acordo com Amanajás e Braga (2012), conhecer a variabilidade pluviométrica é capaz de dar informações sobre o clima, essenciais para o planejamento de atividades humanas e desenvolvimento local. Nesta região, o regime pluviométrico já foi analisado pelos autores: Azevedo et al. (2017), através do prognóstico sazonal da precipitação regionalizada na Amazônia Oriental; Identificação de regiões pluviométricas homogêneas por Amanajás e Braga (2012) e Menezes et al. (2015); Moraes et al. (2005), na análise espacial e temporal da precipitação. Segundo Moraes et al. (2015), a variação temporal e espacial da precipitação no Pará é considerável, as maiores precipitações anuais ocorrem na porção norte, enquanto à Sudeste ocorrem as menores.

Neste contexto, este estudo teve como objetivo analisar e comparar o comportamento pluviométrico no estado do Pará, no período de 1986 a 2015, com base nos dados de precipitação de estações pluviométricas fornecidas pela ANA e nos dados de reanálise de satélites de alta resolução, fornecido pelo GPCC. Assim, por meio destes avaliou-se a dinâmica espaço-temporal da precipitação anual e mensal do estado, após verificou-se o desempenho das estimativas por meio de análises estatísticas, com o intuito que os resultados desta pesquisa contribuam para o detalhamento da variabilidade pluviométrica de longo período e sirva como subsídio para gestão e planejamento dos recursos hídricos do estado do Pará.

\section{MATERIAL E MÉTODOS}


Para o desenvolvimento foi realizada pesquisa para levantamento de informações e dados. A Figura 1, apresenta os procedimentos metodológicos para alcançar o objetivo desta.

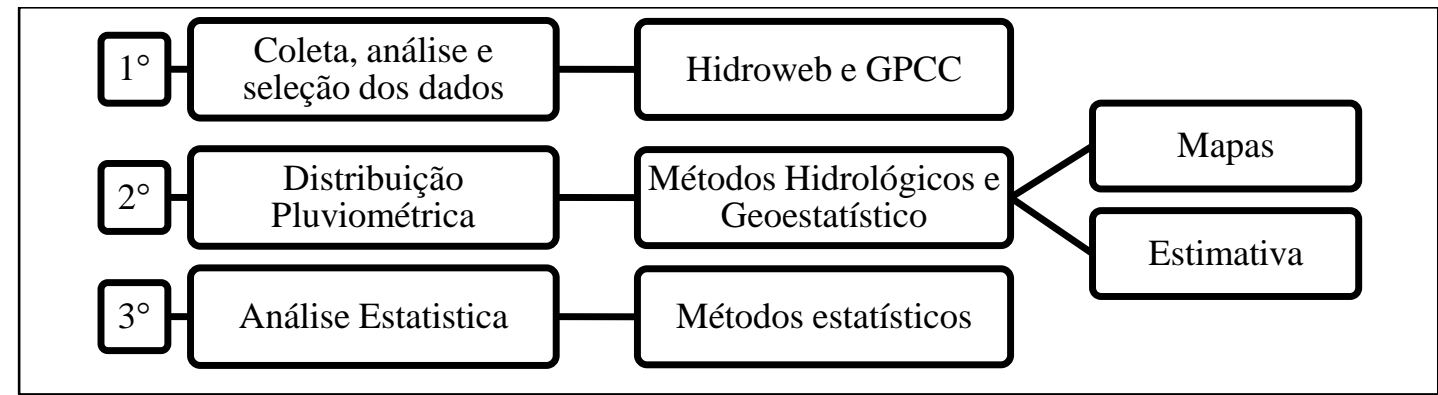

Figura 1 - Esquema Metodológico para análise Pluviométrica no Pará.

\section{1. ÁREA DE ESTUDO}

Compreende o estado do Pará, localizado na região Norte do Brasil (Figura 2), o segundo maior do país em extensão territorial, possuindo uma população de aproximadamente 8,5 milhões de habitantes (IBGE, 2010). Pela classificação de Köppen-Geiger (1928), a região pertence ao clima tipo " $A$ ", designado a climas tropicais com altos índices pluviométricos e com temperaturas médias maiores a $18{ }^{\circ} \mathrm{C}$. Na subclasse de clima equatorial (Af), segundo Menezes et al. (2015), as temperaturas médias anuais estão entre 24 ${ }^{\circ} \mathrm{C}$ e $26^{\circ} \mathrm{C}$, com altos índices pluviométricos, próximos de $2.000 \mathrm{~mm}$ anuais em algumas análises.

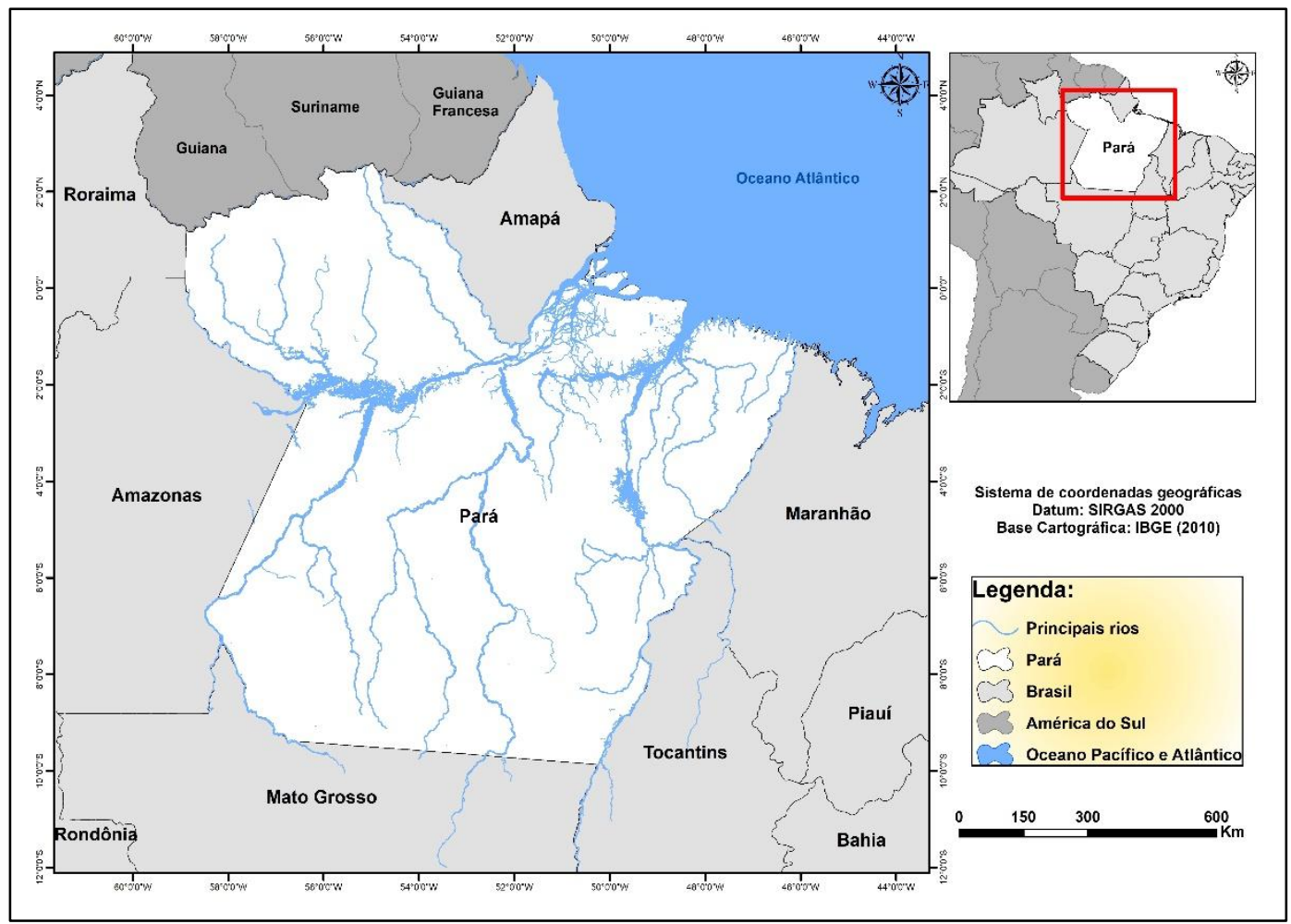


Figura 2 - Localização da área de estudo - estado do Pará.

\subsection{COLETA, ANÁLISE E SELEÇÃO DOS DADOS}

$\mathrm{Na}$ análise pluviométrica, utilizou-se dois conjuntos de dados de precipitação (Figura 3). Ambos com período comum de abrangência das séries de janeiro de 1986 a dezembro de 2015. Seguindo a Organização Mundial de Meteorologia (OMM, 1984), que recomenda para os cálculos dos padrões climatológicos é necessário período de no mínimo três décadas consecutivas.

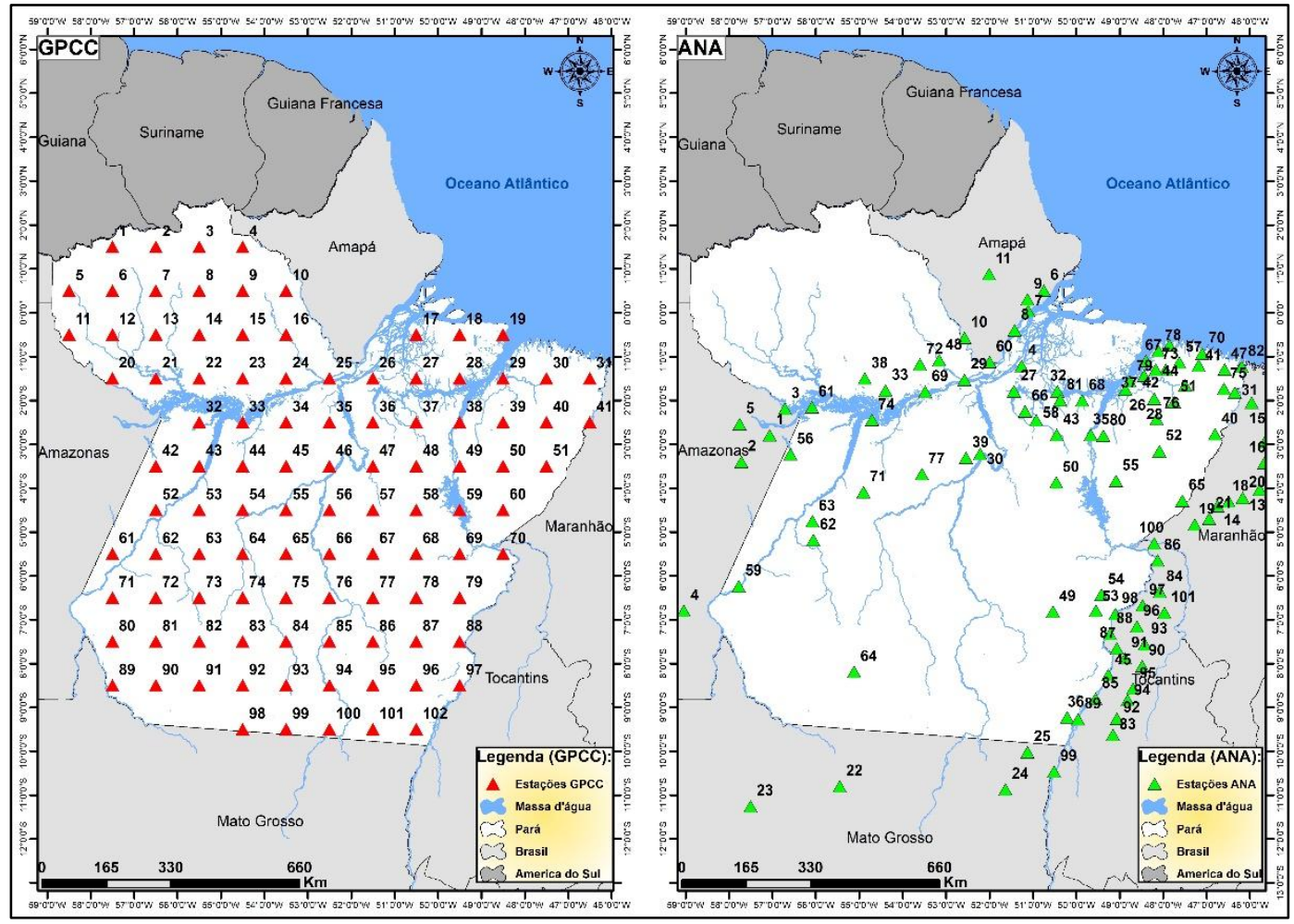

Figura 3 - Localização dos pontos de extração dos dados (GPCC e ANA).

\subsection{CENTRO DE CLIMATOLOGIA DE PRECIPITAÇÃO GLOBAL (GPCC)}

Em 1989 a OMM constituiu o GPCC, operado pelo Serviço Meteorológico Nacional da Alemanha (DWD), para fornece a análise da precipitação global auxiliando no monitoramento e pesquisa do clima da Terra. O centro é uma contribuição alemã para o Programa Mundial de Pesquisa Climática (WCRP) e para o Sistema Global de Observação Climática (GCOS).

A base de dados de monitoramento da GPCC é resultado da união de três fontes de dados, são os totais precipitados mensais derivados de relatórios meteorológicos sinópticos (SYNOP) do DWD da Alemanha, da Administração Nacional Oceânica e Atmosférica (NOAA) do EUA e dos boletins climatológicos DWD da agência Meteorológica do Japão (JMA) e do Serviço Nacional de Meteorologia do Reino Unido (Met. Office UK).

Este são dados de reanálises frutos de modelos climáticos que se ajustam aos dados de campo e interpolam os campos de precipitação. Segundo Schneider et al. (2011), um dos objetivos do GPCC é fornecer ao público, dados 
de precipitação mensal e anual, disponível com resolução espacial de $1^{\circ} \times 1^{\circ} \mathrm{e}$ $2,5^{\circ} \times 2,5^{\circ}$ latitude por longitude, desde 1901 até os dias atuais, interpolados e calculados por 13 métodos estatísticos, disponíveis no site da NOAA.

\subsection{AGÊNCIA NACIONAL DE ÁGUAS (ANA)}

No portal HidroWeb da ANA, foram selecionadas as séries históricas de 101 estações pluviométricas, descritas a seguir na Tabela 1. Estes dados são medidos pontualmente e tem a vantagem da precisão, entretanto a desvantagem da necessidade de alta densidade para representação espacial. Então destas apenas 57 estações estão localizadas no estado do Pará e o restante são estações de estados que fazem fronteira, utilizados para a espacialização.

Tabela 1 - Estações Pluviométricas utilizadas.

\begin{tabular}{|c|c|c|c|c|c|c|c|c|c|c|c|}
\hline $\mathrm{N}^{\circ}$ & UF & Código & $\mathrm{N}^{\circ}$ & UF & Código & $\mathrm{N}^{\circ}$ & UF & Código & $\mathrm{N}^{\circ}$ & UF & Código \\
\hline 1 & AM & 257001 & 26 & PA & 148010 & 51 & PA & 247003 & 76 & PA & 248003 \\
\hline 2 & AM & 357001 & 27 & PA & 151001 & 52 & PA & 348001 & 77 & PA & 353000 \\
\hline 3 & AM & 256002 & 28 & PA & 148009 & 53 & PA & 649001 & 78 & PA & 48006 \\
\hline 4 & AM & 658000 & 29 & PA & 152005 & 54 & PA & 649000 & 79 & PA & 148011 \\
\hline 5 & AM & 257000 & 30 & PA & 352001 & 55 & PA & 349002 & 80 & PA & 249002 \\
\hline 6 & $\mathrm{AP}$ & 8050000 & 31 & $\mathrm{PA}$ & 146008 & 56 & PA & 356002 & 81 & PA & 250001 \\
\hline 7 & AP & 8051002 & 32 & PA & 150003 & 57 & PA & 147010 & 82 & PA & 146009 \\
\hline 8 & $A P$ & 51002 & 33 & PA & 154000 & 58 & PA & 250002 & 83 & TO & 949000 \\
\hline 9 & $\mathrm{AP}$ & 8051010 & 34 & $\mathrm{PA}$ & 151002 & 59 & $\mathrm{PA}$ & 657000 & 84 & TO & 648001 \\
\hline 10 & $A P$ & 52000 & 35 & PA & 249003 & 60 & PA & 151000 & 85 & TO & 849002 \\
\hline 11 & $A P$ & 8052000 & 36 & PA & 950001 & 61 & $\mathrm{PA}$ & 256001 & 86 & TO & 548000 \\
\hline 12 & $\mathrm{MA}$ & 245001 & 37 & $\mathrm{PA}$ & 148002 & 62 & PA & 555000 & 87 & TO & 749000 \\
\hline 13 & $\mathrm{MA}$ & 445001 & 38 & PA & 154001 & 63 & PA & 455003 & 88 & TO & 749001 \\
\hline 14 & $\mathrm{MA}$ & 446001 & 39 & PA & 352005 & 64 & PA & 855000 & 89 & TO & 950000 \\
\hline 15 & $\mathrm{MA}$ & 245003 & 40 & $\mathrm{PA}$ & 247005 & 65 & $\mathrm{PA}$ & 447001 & 90 & TO & 848000 \\
\hline 16 & $\mathrm{MA}$ & 345013 & 41 & PA & 147002 & 66 & PA & 00 & 91 & TO & 748001 \\
\hline 17 & $\mathrm{MA}$ & 345006 & 42 & PA & 147007 & 67 & PA & 148012 & 92 & TO & 949001 \\
\hline 18 & $\mathrm{MA}$ & 446000 & 43 & PA & 250000 & 68 & PA & 149003 & 93 & TO & 748002 \\
\hline 19 & $\mathrm{MA}$ & 447002 & 44 & PA & 147011 & 69 & PA & 153000 & 94 & TO & 848001 \\
\hline 20 & $\mathrm{MA}$ & 346002 & 45 & PA & 849000 & 70 & PA & 47004 & 95 & TO & 848002 \\
\hline 21 & MA & 446002 & 46 & PA & 47003 & 71 & PA & 455004 & 96 & TO & 748003 \\
\hline 22 & MT & 1055002 & 47 & PA & 146010 & 72 & PA & 253000 & 97 & TO & 648002 \\
\hline 23 & MT & 1157001 & 48 & PA & 152006 & 73 & PA & 148003 & 98 & TO & 649003 \\
\hline 24 & MT & 1051001 & 49 & PA & 650001 & 74 & PA & 254000 & 99 & TO & 1050002 \\
\hline 25 & MT & 951000 & 50 & PA & 350000 & 75 & PA & 146005 & 100 & TO & 548001 \\
\hline- & - & - & - & - & - & - & - & - & 101 & TO & 647001 \\
\hline
\end{tabular}

Fonte: HidroWeb (2019).

Algumas estações tiveram limitações referentes a quantidade de dados no período analisado, devido à presença de falhas nas séries históricas. Deste 
modo, para viabilizar está análise optou-se por realizar o preenchimento de falhas das séries mensais, utilizado o método de ponderação regional, conforme Equação (1) apresentado por Tucci (2007). O método é simplificado, no entanto, seus resultados são bastante representativos quando aplicados a regiões climatológicas homogêneas (OLIVERIA et al. 2010; ISHIHARA et al., 2014).

$$
Y=\frac{1}{3} *\left(\frac{x_{1}}{x m_{1}}+\frac{x_{2}}{x m_{2}}+\frac{x_{3}}{x m_{3}}\right) * Y m
$$

Onde: $Y$ é a precipitação a ser estimada; $X 1, X 2$ e $X 3$ são as precipitações correspondente ao mês que se deseja preencher, das três estações vizinhas; Ym - Precipitação média da estação com falha; Xm1, Xm2 e Xm3 são as precipitações médias nas três estações vizinhas.

Portanto, visando à homogeneização do período de informações e à análise estatística das precipitações, utilizou-se estações pluviométricas próximas, com distâncias máximas de 100 km, e da mesma área climatológica da classificação de Koppen como realizados por Bier; Ferraz (2017). Assim, as falhas mensais foram preenchidas, obtendo-se séries de 30 anos com dados contínuos.

Estas áreas hidrologicamente homogêneas são regiões que dividem uma extensão geográfica maior, agrupadas conforme a semelhança de suas particularidades hidrológicas como, por exemplo, a proximidade espacial e características climáticas (CHOUAIB et al., 2018).

Destaca-se que no trabalho de Oliveira et al. (2010), que comparou diferentes metodologias de preenchimento de falhas pluviométricas, o método de ponderação regional apresentou bons resultados pois constatou-se menores desvios relativos entre os valores observados e os estimados. No estudo apresentado por De Mello et al. (2017), está entre os métodos com os melhores resultados, e apresentou desvio relativo médio de $20 \%$.

\subsection{DINÂMICA ESPACIAL E TEMPORAL}

Neste estudo foram empregados métodos baseados na hidrologia e na geoestatística para avaliar a precipitação na escala temporal (ao longo do ano) e espacial (ao longo do estado), a partir das séries históricas dos dois conjuntos de dados, GPCC e ANA. Para isso, foram elaborados mapas pluviométricos através do método de interpolação e estimou-se a precipitação média através das normais climatológicas.

Os principais métodos utilizados para a interpolação da precipitação são Distância Inversa do quadrado (IDW), a interpolação polinomial global e local, a base radial funções ou krigagem (Simples; linear ordinária; Universal e cokrigagem) (ISHIHARA et al., 2014). Entretanto, na elaboração dos mapas, com auxílio de ferramentas de Sistemas de Informações geográficas (SIG), usou-se o método de interpolação de Krigagem ordinária, metodologia semelhante foi adotada nos estudos de Ishihara et al. (2014); Lundgren et al. (2017); Medeiros et al. (2017).

Segundo Mello e Oliveira (2016), é a técnica melhor empregada pelos dados analisados, precipitação, por causa de sua simplicidade e os resultados que origina. Além disto, existem outras particularidades que permitem que a 
mesma seja considerada um excelente estimador no uso de interpolações, visto que não é um estimador tendencioso e, ao mesmo tempo, possui a variância mínima das estimativas (LUNDGREN et al., 2017). Ferreira Filho et al. (2019a), utilizaram 2 métodos para interpolar chuvas, e o que atestou melhor resultado foi a krigagem.

Conforme Medeiros et al. (2017) o método de krigagem já vem sendo utilizado para analisar a distribuição espacial da precipitação pluvial em diversos locais do Brasil, como em Ferreira Filho et al (2019a,b), no Pará e Acre. Atualmente esta técnica é amplamente utilizada no mapeamento da precipitação, principalmente para previsão em locais não amostrados, de forma a espacializar tal informação a título de conhecimento hidrológico (DAS et al., 2017; GUPTA et al., 2017)

Martin e Simpson (2005) afirmam que o método da krigagem também são uma boa opção para aproximar modelos determinísticos de computador porque eles podem interpolar os pontos de dados observados ou conhecidos.

\subsection{DESEMPENHO DA ESTIMATIVA}

Para análise do desempenho das estimativas da precipitação entre as estações e o satélite, utilizou-se uma malha de mil pontos gerados sobre os mapas de interpolação, para a correlação. Além disto, foram aplicados alguns critérios estatísticos, a saber: o Coeficiente de Correlação (R) e Determinação $\left(R^{2}\right)$ usados para medir a concordância geral; o Erro Quadrático Médio (MSE) e a Raiz do Erro Quadrático Médio (RMSE) utilizados para verificar o erro e a predisposição dos dados; e o Coeficiente de Nash-Sutcliffe (NASH) empregado para avaliar a eficiência entre as estimativas (Tabela 2).

Tabela 2 - Estatísticas para Desempenho da Estimativa.

\begin{tabular}{|c|c|c|c|c|}
\hline Métodos & Equação & Intervalo & Valor Ótimo & $\mathbf{N}^{\circ}$ Equação \\
\hline $\mathrm{R}$ & $R=\frac{\sum(P i-\bar{P} l)(P i y-\overline{P l y})^{2}}{\left.\sqrt{\sum(P i-\bar{P})^{2}} \sqrt{\sum(P i y-\bar{P} \imath y}\right)^{2}}$ & -1 a 1 & 1 & (2) \\
\hline $\mathrm{R}^{2}$ & $R^{2}=\frac{\sum(P i y-\bar{P})^{2}}{\sum(P i-\bar{P})^{2}}$ & 0 a 1 & 1 & (3) \\
\hline MSE & $M S E=\frac{1}{\mathbf{N}} \sum(P i-P i y)^{2}$ & 0 a $\infty$ & 0 & (4) \\
\hline RMSE & $\mathrm{R} M S E=\left[\frac{1}{\mathrm{~N}} \sum(P i-P \boldsymbol{i} y)^{2}\right]^{1 / 2}$ & 0 a $\infty$ & 0 & (5) \\
\hline $\mathrm{NASH}$ & $N A S H=1-\frac{\sum_{i=1}^{n}(P i-P i y)^{2}}{\sum_{i=1}^{n}(P i-\bar{P})^{2}}$ & $-\infty$ a 1 & 1 & (6) \\
\hline
\end{tabular}

Nota: Onde Pi é a precipitação da ANA, Piy é a precipitação GPCC.

O coeficiente $\mathrm{R}$ de Pearson foi determinado pela (Eq. 1) e pode variar de -1 (correlação perfeita negativa), +1 (correlação perfeita positiva), passando pelo valor 0 (ausência de correlação). Assim, conforme classificação sugerida por Fonseca et al. (2010), as correlações R podem ser: 0,00 a 0,19 (bem fraca); 0,20 a 0,39 (fraca); 0,40 a 0,69 (moderada); 0,70 a 0,89 (forte); 0,90 a 1,0 (muito forte). 
O coeficiente de determinação $\left(R^{2}\right)$ é um critério estatístico que mede a proporção da variação de $Y$ (variável dependente) que pode ser explicada pela variável $X$ (variável independente). $O$ valor de $R^{2}$ pode variar de 0 a $1, \log 0,0 \leq$ $\mathrm{R}^{2} \leq 1$ (CRISPIM et al., 2019).

Outro critério empregado para os ajustes dos resultados foi o coeficiente de Nash-Sutcliffe (NASH), os quais os picos de chuvas foram desconsiderados das análises por apresentarem valores extremos e isolados. Assim, foi utilizada uma classificação sugerida por Costa et al. (2019) e Pereira et al. (2016): valores bons (NASH >0,75); aceitáveis $(0,36 \leq \mathrm{NASH} \leq 0,75)$; inapropriados (NASH < 0,36). A RMSE foi aplicada para retratar a diferença entre os valores de precipitação (COSTA et al., 2019).

\section{RESULTADOS E DISCUSSÃO}

\subsection{PRECIPITAÇÃO ANUAL}

Para analisar o comportamento da variabilidade pluviométrica no estado do Pará, foram distribuídas a precipitação média anual para o período de 1986 a 2015, apresentadas na Figura 4. Com base nos resultados obtidos por meio dos dados do GPCC, observa-se que as maiores precipitações médias anuais foram registradas na parte nordeste do estado do Pará, onde estão localizadas as mesorregiões do Marajó, Metropolitana de Belém e um trecho do Nordeste Paraense, bem como um trecho abrangendo a mesorregião do Baixo Amazonas.

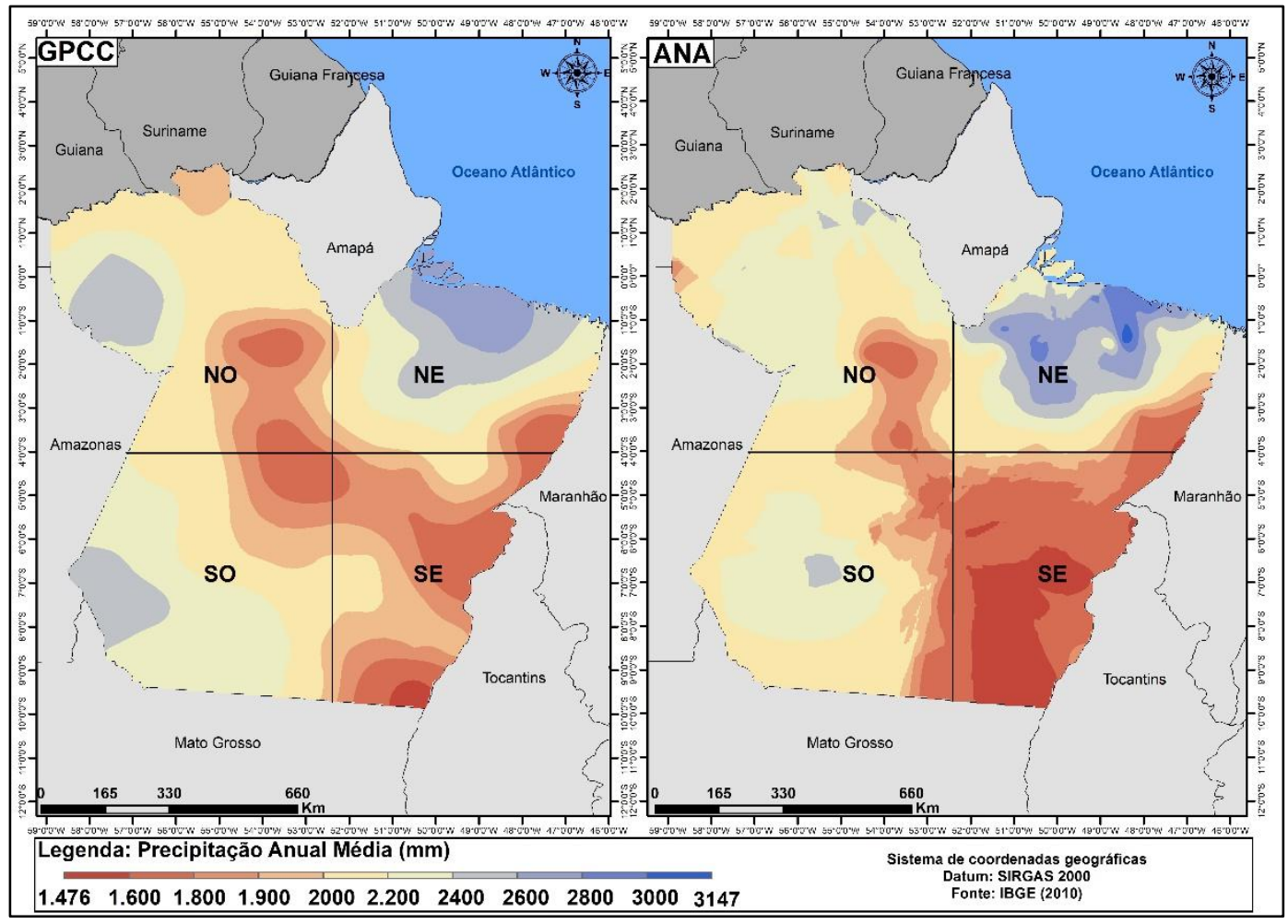

Figura 4 -Precipitação anual média de longo período do estado do Pará (1986 a 2015).

Estes resultados apresentam semelhanças aos obtidos por Amaral et al. (2016) e Albuquerque et al. (2010), no qual constataram que as maiores 
precipitações médias anuais foram na parte nordeste do estado, abrangendo áreas inseridas nestas três mesorregiões, bem com uma porção na mesorregião do Baixo Amazonas.

Segundo Albuquerque et al. (2010), a questão do fato dos maiores índices pluviométricos serem registrados na parte nordeste do estado se dá pela atuação de sistemas de grande-proporção como, por exemplo, Zona de Convergência Intertropical (ZCIT), forte convecção local e por encontrar-se próxima do litoral.

Para Pontes et al. (2017) e Souza et al. (2009) a variação climática interanual e sazonal do período chuvoso no trecho da Amazônia Oriental é resultante da interferência direta do acoplamento oceânico. Estes autores comungam da mesma linha de raciocínio de Albuquerque et al. (2010) no tocante a influência de fenômenos de grande-escala que ocorrem nos oceanos, a título de exemplo, ZCIT, mas, acrescentam as Linhas de Instabilidades (LIs).

Os resultados alcançados pelo GPCC e ANA, evidenciam que os menores índices de precipitações foram registrados na parte sudeste do estado, com valores inferiores a $1.476 \mathrm{~mm}$. Estes resultados são similares aos alcançados por Amaral et al. (2016) e Albuquerque et al. (2010), no qual também constataram que os menores índices de precipitação foram identificados na região sudeste do estado do Pará, com valores inferiores, respectivamente de $1.600 \mathrm{~mm}$ e $1.900 \mathrm{~mm}$.

Comparando os regimes pluviométricos nota-se semelhança na distribuição espacial, porém, as regiões noroeste e sudoeste apresentaram pequenas diferenças, pois, são áreas de baixa densidade de estações da ANA, enquanto o GPCC tem uma boa distribuição da malha de dados na região. Mas, as precipitações anuais médias são próximas, pela ANA estimou-se média de $2.075 \mathrm{~mm} /$ ano e pelo GPCC média de $2.109 \mathrm{~mm} / \mathrm{ano}$, ou seja, $34 \mathrm{~mm}$ de diferença entre os conjuntos de dados $(1,6 \%)$. Sendo que as precipitações mínimas também tiveram pequena diferença de $8 \mathrm{~mm}(0,5 \%)$, pois, na espacialização da ANA foi de $1.467 \mathrm{~mm}$ /ano e pelo GPCC $1.475 \mathrm{~mm} / \mathrm{ano}$. Entretanto, as precipitações máximas apresentaram diferença de $466 \mathrm{~mm}$ $(17 \%)$, pois, se estimou pela ANA 3.147 mm/ano e pelo GPCC $2.681 \mathrm{~mm} / \mathrm{ano}$.

Os resultados confirmam que o regime pluviométrico no estado do Pará não é homogêneo. Vários estudos já comprovaram que a variabilidade pluviométrica da região está relacionada aos sistemas e fenômenos atmosféricos atuantes (PONTES et al., 2017; MENEZES et al., 2015; SOUZA et al., 2009; MORAES et al., 2005).

Estas distinções entre os conjuntos de dados reconstruídos e os dados observados da ANA decorrem da aplicação de diversos métodos estatísticos na compilação dos dados e dos diferentes conjuntos de dados primários compilados, tal como discutem Carvalho et al. (2012), e das médias espaciais aplicadas (LIMBERGER; SILVA, 2018).

Para verificar o desempenho das estimativas da precipitação da ANA e do GPCC, a partir da espacialização, gerou-se uma malha de 1 mil pontos aleatórios e extraíram-se os valores pontuais de precipitação, no qual foram analisados. Logo, os valore do $(R)$ foi de 0,82 e $\left(R^{2}\right) 0,67$, demonstrando que há uma concordância entre os dados. Com relação aos erros, estes tiveram uma média 
de $28 \mathrm{~mm}$, MSE de 31.180 e RMSE 176,6, indicando que existe uma pequena diferença entre os dados, já que se trata de valores altos de precipitação anual.

O Coeficiente de NASH apresentou um valor de 0,65, logo, constata-se que os resultados obtidos neste critério, bem como nos demais são aceitáveis com base nos valores de (R), ( $\left.R^{2}\right)$ e NASH, conforme (COSTA et al., 2019; PEREIRA et al., 2016). Os testes estatísticos demonstram que os valores dos dados das duas fontes são próximos. Porém, há uma diferença, que pode ser justificada por diversos motivos como, por exemplo, erros de capturas das imagens de satélites, devido à formação de nuvens carregada na área.

\subsection{PRECIPITAÇÃO MENSAL}

De acordo com as informações obtidas pelo GPCC e ANA para o período observado (1986 a 2015), foi realizado a interpolação destes dados com o propósito de espacializar o comportamento da precipitação média mensal (Figura 5). Assim, conforme os resultados alcançados constatam-se que a sazonalidade apresentou comportamentos similares para o GPCC e ANA. Além disto, verifica-se que em ambas as elevações dos índices pluviométricos pluviométrico se iniciam em dezembro na parte sul do estado.

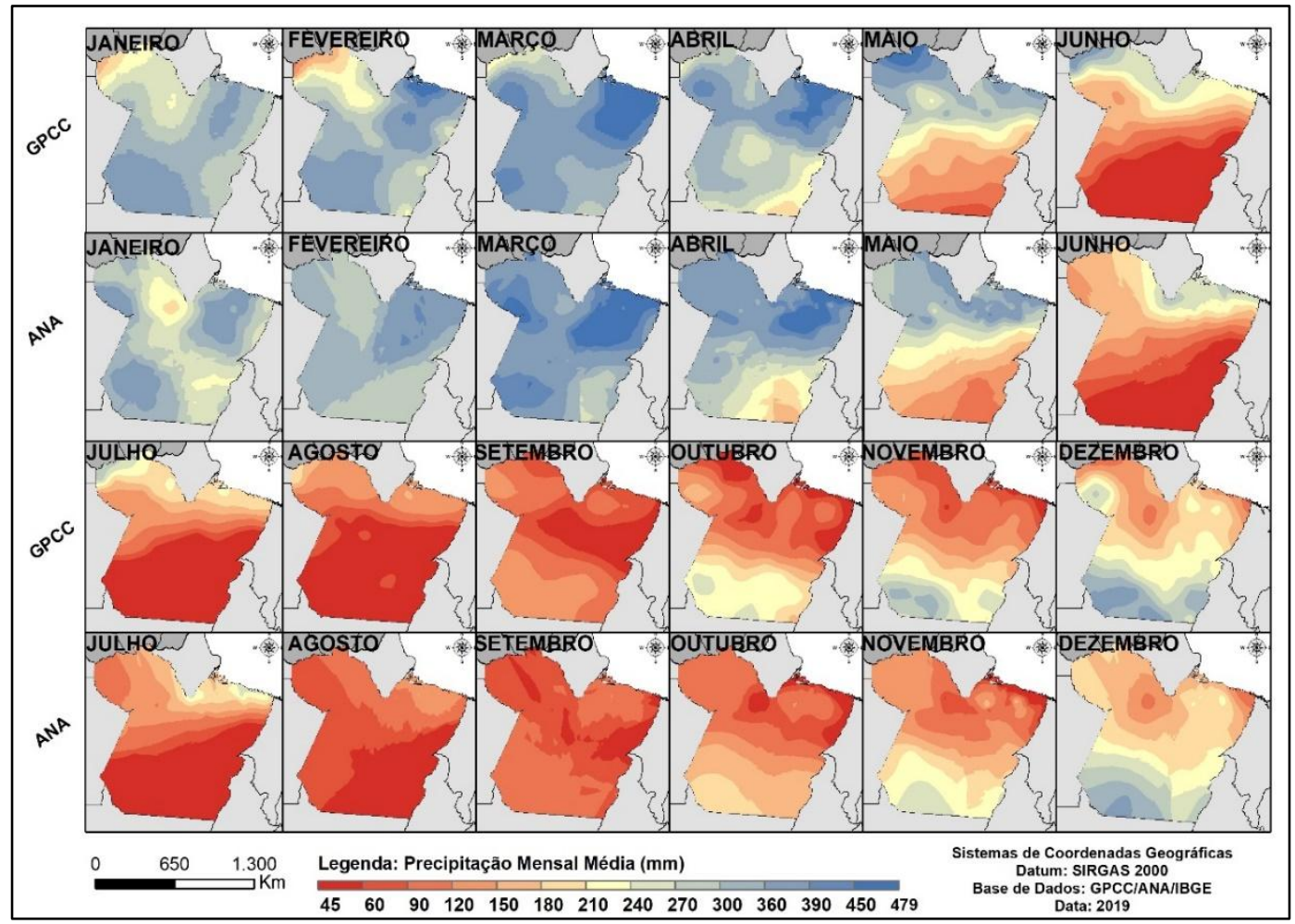

Figura 5 - Precipitação Mensal Média de longo período do Pará (1986 a 2015).

No geral, pode-se observar a boa consistência entre as diferentes fontes de dado, pois, o comportamento da precipitação foi semelhante. Todavia, na região sul do estado existe uma pequena diferença, que pode estar associada ao fato de que a rede de monitoramento da ANA possui uma baixa cobertura e menor densidade de pontos para coleta de dados. Ao contrário do GPCC, que tem uma boa distribuição dos pontos na extensão territorial do estado para 
obter as informações, pois, é estimado através de uma malha. Logo, constatase que este minimiza o problema da baixa densidade de estações em determinados lugares dentro do estado.

Outra possibilidade que pode ser levantada neste resultado consiste que em alguns casos, um fenômeno climático ou a combinação deles estejam presentes apenas durante alguns meses do ano, provocando variações, quase que exclusivamente em determinado momento, e que podem ser atenuados no decorrer do tempo, de maneira que as análises de precipitações anuais não evidenciam (LOPES; DE SOUZA; FERREIRA, 2013).

Posteriormente a interpolação dos dados de precipitações mensais para ambos os métodos, foram gerados uma malha de 1 mil pontos aleatórios bem distribuídos na área para extração dos dados e a realização dos testes estatísticos. Assim, na Figura 6 são ilustrados os resultados da comparação do desempenho entre as estimativas de precipitação mensal da ANA e do GPCC, gerados da análise dos valores pontuais aleatórios.

Nota-se que $\mathrm{R}$ e $\mathrm{R}^{2}$ apresentaram algumas variações. Logo, constata-se que com relação ao critério estatístico $R$ os meses de janeiro, fevereiro $e$ setembro apresentaram uma correlação moderada $(0,40 \leq R \leq 0,69)$, março, abril, junho e julho demonstraram uma correlação forte $(0,70 \leq R \leq 0,89)$, enquanto os meses de maio, outubro, novembro e dezembro apresentaram uma correlação muito forte $(0,90 \leq R \leq 1,00)$.

No tocante ao $R^{2}$, verifica-se que os meses de janeiro e setembro demonstraram valores de coeficientes classificados como insatisfatórios $(0,36<$ $\left.R^{2}\right)$, enquanto os demais apresentaram valores de coeficientes aceitáveis $(0,36$ $\left.\leq R^{2} \leq 0,75\right)$ e bons $\left(R^{2}>0,75\right)$, com notoriedade também para o mês de novembro $\left(R^{2}=0,91\right)$.

Com relação ao teste estatístico de NASH verifica-se que os meses de janeiro, fevereiro, agosto, setembro e outubro apresentaram desempenhos insatisfatórios, com destaque para o mês de setembro ( $\mathrm{NASH}=-3,04$ ), enquanto os demais meses apresentaram coeficientes classificados como aceitáveis $(0,36 \leq \mathrm{NASH} \leq 0,75)$ e bons (NASH $>0,75)$. Com relação ao MSE e RMSE constatou-se que o menor erro foi referente ao mês de setembro, no qual apresentou respectivamente, valores de 538,78 e 23,21, enquanto o maior erro foi no mês de fevereiro, em que os valores obtidos foram de 1.942,56 e 44,07. 

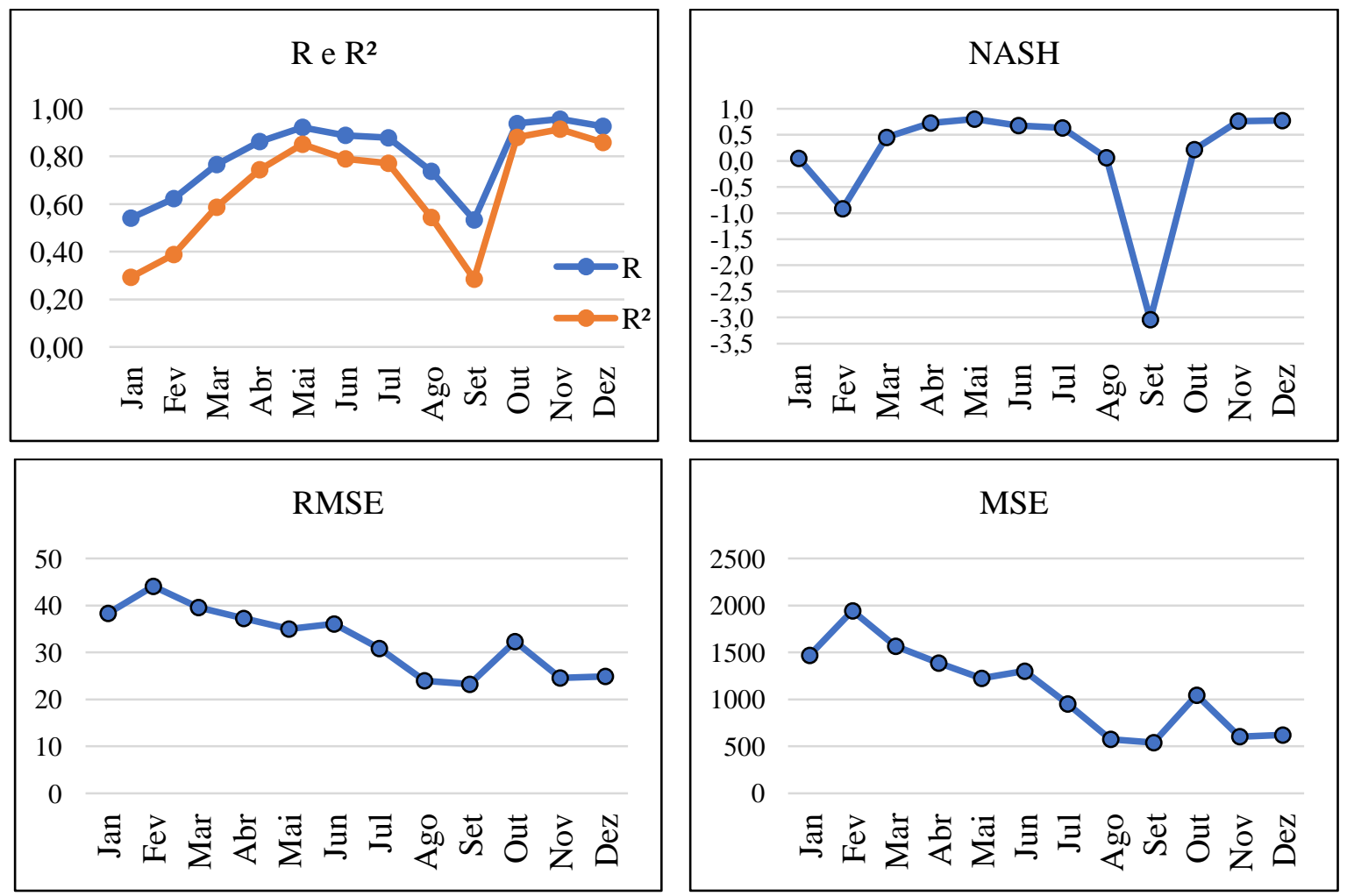

Figura 6 - Resultado do desempenho das estimativas da precipitação Mensal.

$\mathrm{Na}$ análise do comportamento sazonal pluviométrico utilizando a normal climatológica para o estado do Pará (Figura 7), observa-se a existência de duas estações bem distintas, isto é, uma estação chuvosa e outra menos chuvosa. Assim, verifica-se que os resultados alcançados neste estudo no tocante a sazonalidade é similar aos obtidos por Amaral et al. (2016) e Menezes et al. (2015) no qual realizaram estudos sobre a precipitação pluvial no estado do Pará.

Outro resultado semelhante deste estudo com os achados das pesquisas de Amaral et al. (2016) e Menezes et al. (2015) consiste nos meses com os maiores registros de precipitação no período chuvoso, pois, tanto neste estudo como das pesquisas citadas o trimestre mais chuvoso abrange os meses de fevereiro, março e abril. Além disto, em ambas as pesquisas se constatou que o mês com os maiores volumes de precipitação pluviométrica foi março, alcançando índices superior a $350 \mathrm{~mm}$.

A análise estatística dos dados médios mensais anuais, gerou um valor de 0,94 para o Coeficiente de Correlação de Pearson (R), sendo considerado um resultado excelente conforme Pereira et al. (2016). Logo, constata-se que o valor obtido neste estudo para este critério estatístico é similar ao alcançado na pesquisa realizada por Limberger e Silva (2018), no qual obtiveram um (R) de 0,98 para a região da foz da bacia do Amazonas, representando uma parte do estado do Pará. 


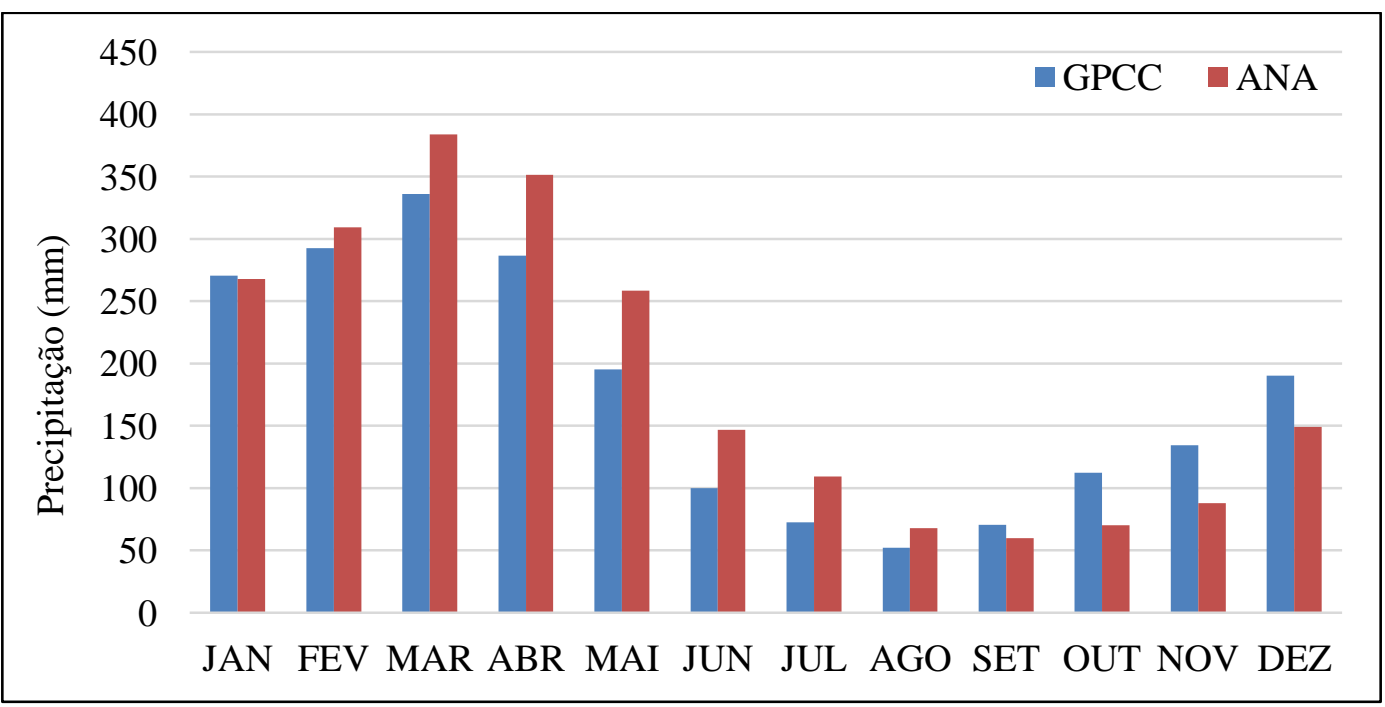

Figura 7 - Normal climatológica do estado do Pará (1986 a 2015).

Outra descoberta similar nesta pesquisa com o estudo feito por Amaral et al. (2016) consiste nos meses com os menores volumes de precipitação, haja vista que em ambos os estudos o bimestre menos chuvoso ocorre nos meses de agosto e setembro, em que foram identificadas as menores médias mensais de chuva para o estado do Pará.

Ao plotar os erros padrões entre as normais climatológicas (Figura 8), observa-se que o GPCC subestima os valores da ANA nos meses de fevereiro a agosto, quando a região apresenta com altos valores de precipitação e superestima nos meses de setembro a janeiro.

A exemplo, o mês de março apresentou em ambos o maior índice mensal, mas, com variação de $47,58 \mathrm{~mm}$. Com destaque para o mês de janeiro que apresentou o menor erro de $2,74 \mathrm{~mm}$ e para o com maior erro em abril, com variação de $64,63 \mathrm{~mm}$. No geral, obteve-se um erro médio de 12,38 mm, não sendo considerado um valor muito discrepante para análise. 


\section{Aumento $\square$ Diminuição $\square$ Total}

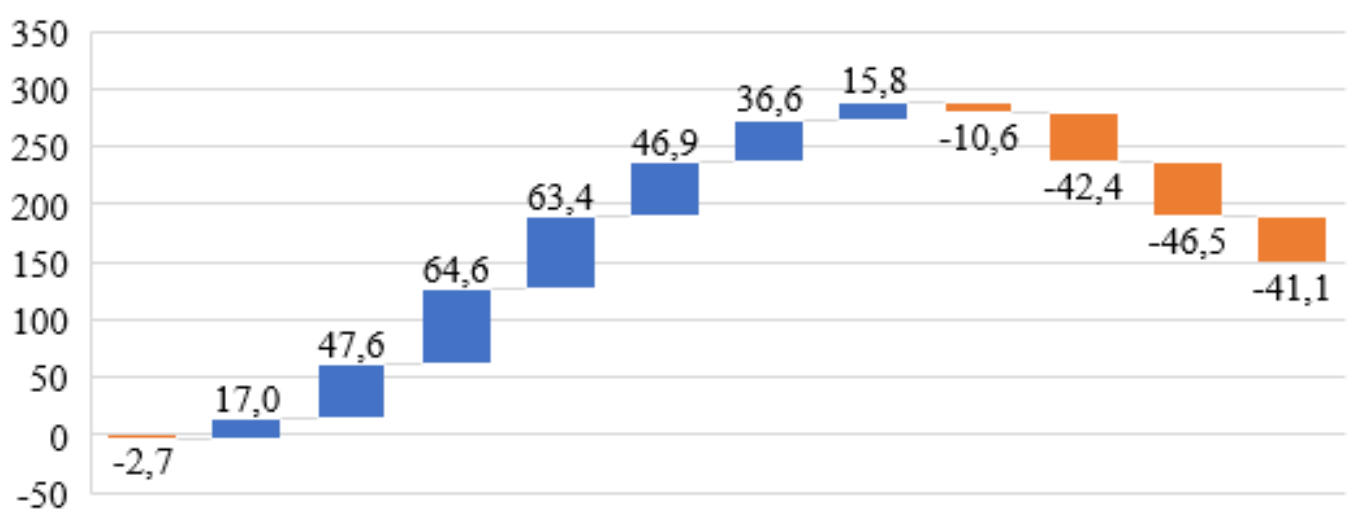

\section{JAN FEV MAR ABR MAI JUN JUL AGO SET OUT NOV DEZ}

Figura 8 - Erro Padrão da Normal climatológica do estado do Pará (1986 a 2015).

$\mathrm{O}$ teste de $\mathrm{R}^{2}$ apresentou um valor de 0,89 , condizente também com 0 Pearson. Confirmando que ambas as fontes de dados apresentam valores representativos e próximos. Vale destacar que apesar de serem próximos, não significam afirmar que os valores absolutos são parecidos, pois, este trata-se do estudo das médias, podem ser utilizados para análises pluviométricas.

\section{CONCLUSÕES}

Neste estudo constatou-se que o monitoramento hidrometeorológico no estado do Pará através de estações pluviométricas apresentam várias dificuldades como, por exemplo, pequena cobertura, baixa densidade, estações desativadas, outras com séries de dados apresentando falhas mensais e anuais, estações não divididas de forma homogênea na área territorial do estado e diversas com um período de operação menor que 30 anos, tornando-se um obstáculo para pesquisas relacionadas aos monitoramento pluviométrico.

A espacialização da distribuição da precipitação média anual para o período de 1986 a 2015 no estado do Pará, através do método de interpolação Krigagem, evidenciou que os maiores índices pluviométricos estão localizados no Nordeste Paraense, abrangendo áreas das mesorregiões do Marajó, Metropolitana de Belém e Nordeste Paraense. Além disto, os resultados obtidos pelo GPCC e ANA, indicaram que os menores índices de precipitações foram observados na porção sudeste do estado.

Os resultados demonstraram uma variabilidade nos padrões de precipitação, em especial, nos totais acumulados, em que estes podem ser influenciados por sistemas de grande-proporção, por exemplo, a Zona de Convergência Intertropical (ZCIT) e Linhas de Instabilidades (LIs).

Os resultados obtidos para a distribuição da média mensal da precipitação do estado do Pará com base nos dados do GPCC e ANA indicaram comportamentos similares para sazonalidade, no qual se observou duas estações bem distintas ao longo dos anos, uma chuvosa e outra menos chuvosa. 
Logo, os meses com maiores registros de precipitação foi fevereiro, março e abril, enquanto os meses menos chuvosos foi agosto e setembro.

Vale ressaltar que estes conjuntos de dados, sejam eles observados ou simulados, apresentam similaridades e dissimilaridades em alguns pontos, é por este motivo, que o presente trabalho, serve de auxílio para análises hidrológicas, haja vista que, dependendo da finalidade, são possíveis comparações entre as bases, com intuito de suplementar informações às futuras pesquisas.

Logo, as utilizações de satélites meteorológicos ganham importância no cenário local e nacional, devido sua constante melhora e aproximação com os valores medidos in loco, assim, esta pesquisa contribuirá para essa nova fase em estudos hidrológicos.

\section{REFERÊNCIAS BIBLIOGRÁFICAS}

ALBUQUERQUE, M.F. DE; SOUZA, E.B. DE; OLIVEIRA, M. DO C.F.; SOUZA JÚNIOR, J.A. Precipitação nas mesorregiões do estado do Pará: Climatologia, variabilidade e tendências nas últimas Décadas (1978-2008). Revista Brasileira de Climatologia, v.6, p.151 - 168, 2010.

AMANAJÁS, J.C.; BRAGA, C.C. Padrões espaço-temporal pluviométricos na Amazônia Oriental utilizando análise multivariada. Revista Brasileira de Meteorologia, v. 27, n. 4, p.423 - 434, 2012.

AMARAL, M.A.C.M. do; JOSÉ, J.V.; FOLEGATTI, M.V.; COELHO, R.D.; BARROS, T.H. da S. Distribuição espacial da precipitação pluviométrica em relação à topografia no estado do Pará. Irriga, Botucatu, Edição Especial, IRRIGA \& INOVAGRI, p. 1-12, 2016.

ANA. Agência Nacional de Águas do Brasil. Conjuntura dos recursos hídricos no Brasil 2017: relatório pleno. Agência Nacional de Águas. - Brasília: ANA, 2017.

AZEVEDO, F.T.M.; SOUZA, E.B.; FRANCO, V.S.; SOUZA, P.F.S. Prognóstico sazonal de precipitação regionalizada na Amazônia Oriental. Revista Brasileira de Geografia Física, v.10, n.05, p. 1520-1534, 2017.

BIER, A. A.; FERRAZ, S. E. T. Comparação de metodologias de preenchimento de falhas em dados meteorológicos para estações no sul do Brasil. Revista Brasileira de Meteorologia, v. 32, n. 2, p. 215-226, 2017.

BRASIL. Lei no 9433, de 8 de janeiro de 1997. Institui a Política Nacional de Recursos Hídricos, cria o Sistema Nacional de Gerenciamento de Recursos Hídricos, regulamenta o inciso XIX do art. 21 da Constituição Federal, e altera o art. $1^{\circ}$ da Lei no 8.001, de 13 de março de 1990, que modificou a Lei no 7.990, de 28 de dezembro de 1989. Disponível em:www.planalto.gov.br/ ccivil_03/Leis/L9433.htm. Acesso em: 21 maio 2019.

CARMELLO, V.; SANT'ANNA NETO, J. L. Variabilidade das chuvas na vertente paranaense da bacia do rio Paranapanema -1999-2000 a 2009-2010. Ra'e Ga Curitiba, v.33, p.225-247, 2015.

CHOUAIB, W.; ALILA, Y.; CALDWELL, P. V. Parameter transferability within homogeneous regions and comparisons with predictions from a priori 
parameters in the eastern United States. Journal of Hydrology, v. 560, p. 24-38, 2018.

CIRINO, L. dos S.; VITORINO, M.I.; HOLANDA, B.S. Análise climática da variabilidade natural e antrópica para uma metrópole amazônica. Rev. Bras. de Iniciação Científica (RBIC), Itapetininga, v. 6, n.2, p. 3-26, 2019.

COSTA, J.C.; PEREIRA, G.; SIQUEIRA, M.E.; DA SILVA CARDOZO, F.; DA SILVA, V.V. Validação dos dados de precipitação estimados pelo CHIRPS para o Brasil. Revista Brasileira de Climatologia, v. 24, p. 228-243, 2019.

CRISPIM, D.L.; RODRIGUES, R.S.S.; VIEIRA, A.S. de A.; SILVEIRA, R.N.P. de O.; PESSOA, F.C.L. Análise estatística da precipitação do município de Brasiléia - Acre, Brasil. Revista Gestão \& Sustentabilidade Ambiental, Florianópolis, v. 8, n. 2, p.104-122, abr/jun. 2019.

DAS, M.; HAZRA, A.; SARKAR, A.; BHATTACHARYA, S.; BANIK, P. Comparison of spatial interpolation methods for estimation of weekly rainfall in West Bengal, India. MAUSAM, v. 68, n. 1, p. 41-50, 2017.

DEE, D.; FASULLO, J.; SHEA, D.; WALSH, J. The climate data guide: atmospheric reanalysis: overview \& comparison tables. Disponível em https://climatedataguide.ucar.edu/climate-data/atmospheric-reanalysisoverview comparison-tables. Acesso em: 4 maio 2019.

FASULLO, J. A mechanism for land-ocean contrasts in global monsoon trends in a warming climate. Climate Dynamics, v. 39, n. 5, p. 1137-1147, 2012.

FERREIRA FILHO, D. F.; BEZERRA, P. E. S.; SILVA, M. de N. A. da.; RODRIGUES, R. S. S.; FIGUEIREDO, N. M. de. Aplicação de técnicas de interpolação para espacialização de chuvas da região hidrográfica Calha Norte, Pará. Revista Brasileira de Climatologia, v. 24 , p. 277 - 299, jan/jun, 2019.

FERREIRA FILHO, D. F.; CRISPIM, D. L.; PESSOA, F. C. L. P.; FERNANDES, L. L. Spatialization of precipitation and analyzes of trends obtained through the GPCC satellite for the state of Acre. Journal of Hyperspectral Remote Sensing, v. 9, n. 2, p. 68-79, 2019b.

GUPTA, A.; KAMBLE, T.; MACHIWAL, D. Comparison of ordinary and Bayesian kriging techniques in depicting rainfall variability in arid and semi-arid regions of north-west India. Environmental Earth Sciences, v. 76, n. 15, e512, 2017.

HARADA, Y.; KAMAHORI, H.; KOBAYASHI, C.; ENDO, H.; KOBAYASHI, S.; OTA, Y.; TAKAHASHI, K. The JRA-55 Reanalysis: Representation of atmospheric circulation and climate variability. Journal of the Meteorological Society of Japan, v. 94, n. 3, p. 269-302, 2016.

HOLTON, J.R. An introduction to dynamic meteorology. American Journal of Physics, v. 41, n. 5, p. 752-754, 1973.

HRACHOWITZ, M.; SAVENIJE, H.; BOGAARD, T.A.; TETZLAFF, D.; SOULSBY, C. What can flux tracking teach us about water age distribution patterns and their temporal dynamics?, Hydrol. Earth Syst. Sci., v.17, n.2, p.533-564, 2013.

IBGE. Instituto Brasileiro de Geografia e Estatística. Censo Demográfico 2010. Rio de Janeiro: IBGE, 2010. Disponível em: https://cidades.ibge.gov.br/brasil/pa/panorama. Acesso em: 12 maio 2020. 
ISHIHARA, J. H.; FERNANDES, L. L.; DUARTE, A. A. A. M.; DUARTE, A. R. C. L. M. ; PONTE, M. X.; LOUREIRO, G. E. Quantitative and Spatial Assessment of Precipitation in the Brazilian Amazon (Legal Amazon) - (1978 to 2007). Revista Brasileira de Recursos Hídricos, Porto Alegre, v. 19, p. 29-39, n. 2014.

KÖPPEN, W.; GEIGER, R. Klimate der Erde. Gotha: Verlag Justus Perthes. 1928.

LIMBERGER, L.; SILVA, M.E.S. Precipitação observada na Amazônia brasileira: comparação entre os dados das redes convencionais edados da reanálise I do NCEP/NCAR, CRU e GPCC. Revista Brasileira de Climatologia, v. 22, p. 20-37, 2018.

LOPES, M. N. G.; DE SOUZA, E. B.; FERREIRA, D. B. DA S. Climatologia regional da precipitação no estado do Pará. Revista Brasileira de Climatologia, Ano 9, v. 12, JAN/JUL 2013.

LUCAS, E.W.M.; SOUSA, F. de A.S. de; SILVA, F.D. dos S.; LUCIO, P. S. Modelagem hidrológica determinística e estocástica aplicada à região hidrográfica do Xingu- Pará. Revista Brasileira de Meteorologia, v.24, n.3, p.308-322, 2009.

LUNDGREN, W.J.C.; SOUZA, I.F. de; LUNDGREN, G.A. Krigagem na construção de mapa pluviométrico do Estado de Sergipe. Revista Brasileira de Geografia Física, v.10, n.1, p. 13-22, 2017.

MARTIN, J. D.; SIMPSON, T. W. Use of kriging models to approximate deterministic computer models. AIAA journal, v. 43, n. 4, p. 853-863, 2005.

MEDEIROS, F.J.; LUCIO, P. S.; SILVA, H.J.F. Análise de Métodos de Krigagem na Estimativa da Precipitação no Estado do Rio Grande do Norte. Revista Brasileira de Geografia Física, Vol. 10, n.5. 2017

MELLO, Y. R. DE; KOHLS, W.; OLIVEIRA, T. M. N. DE. Uso de diferentes métodos para o preenchimento de falhas em estações pluviométricas. Boletim De Geografia, v. 35, n. 1, p. 112-121, 2017. https://doi.org/10.4025/bolgeogr.v35i1.30893.

MENEZES, F.P.; FERNANDES, L.L.; ROCHA, E.J.P. O Uso da Estatística para Regionalização da Precipitação no Estado do Pará, Brasil. Revista Brasileira de Climatologia, v. 16, p. 64-71, 2015. Acesso em: 15 mar. 2018.

MORAES, B.C. de; COSTA, J.M.N. da; COSTA A.C.L. da; COSTA, M.H. Variação espacial e temporal da precipitação no Estado do Pará. Acta Amazônica, v. 35, n. 2, p. 207-214, 2005.

OLIVEIRA JÚNIOR, J. F.; DELGADO, R. C.; LANNES, A.; DIAS, F. O.; SOUZA, C. J.; SOUZA, M. Análise da Precipitação e sua Relação com Sistemas Meteorológicos em Seropédica, Rio de Janeiro. Floresta e Ambiente, Rio de Janeiro, v.21, n.2, p.140-149, 2014.

OLIVEIRA, LUIZ F. C. de et al. Comparação de metodologias de preenchimento de falhas de séries históricas de precipitação pluvial anual. Revista Brasileira de Engenharia Agrícola e Ambiental, v.14, n.11, p.1186-1192, 2010.

OLIVEIRA, LUIZ F. C. de et al. Comparação de metodologias de preenchimento de falhas de séries históricas de precipitação pluvial anual. Revista Brasileira de Engenharia Agrícola e Ambiental, v.14, n.11, p.1186-1192, 2010. 
OMM. Organización Meteorológica Mundial. Guia de Prácticas Hidrológicas. Aquisicion y Processo de Dados. 4. ed. Genebra, 1984.

PEREIRA, D. dos R.; ULIANA, E.M.; MARTINEZ, M.A.; DA SILVA, D.D. Desempenho de um modelo hidrológico concentrado e de um semidistribuído na predição de vazões diárias. Irriga, Botucatu, v. 21, n. 2, p.409-424, 2016.

PONTES, M.L.C.; LIMA, A.M.M.; SILVA JÚNIOR, J.D.A.; AZEVEDO SADECK, C.C. Dinâmica das áreas de várzea do município de Belém/PA e a influência da precipitação pluviométrica na formação de pontos alagamentos. Caderno de Geografia, v. 27, n. 49, p. 285-303, 2017.

SCHNEIDER, U.; BECKER, A.; MEYER-CHRISTOFFER, A.; RUDOLF, B. Global Precipitation Analysis Products of the GPCC. Global Precipitation Climatology Centre (GPCC) Deutscher Wetterdienst, Offenbach a. M., Germany, 2011.

SOUSA, A. M. L.; ROCHA, E. J. P.; VITORINO, M. I.; SOUZA, P. J. O. P.; BOTELHO, M. N. Variabilidade espaço-temporal da precipitação na Amazônia durante eventos ENOS. Revista Brasileira de Geografia Física, v. 8, p. 15-29, 2015.

SOUZA, E. B. et al. Precipitação sazonal sobre a Amazônia oriental no período chuvoso: observações e simulações regionais com o RegCM3. Revista Brasileira de Meteorologia, v. 24, n. 2, p. 111-124, 2009.

TEIXEIRA, C.A.; ZATTONI, G.T.; NAGALI, A.; FREIRE, F.; TEIXEIRA, S. Análise de viabilidade técnica e econômica do uso de água de chuva em uma indústria metalmecânica na região metropolitana de Curitiba PR. Gestão \& Produção, v. 23, n. 3, p. 638-648, 2016.

TRENBERTH, K.E.; FASULLO, J.; MACKARO, J. Atmospheric moisture transports from ocean to land and global energy flows in reanalysis. Journal of Climate, v. 24, p. 4907-4924, 2011.

TUCCI, C.EM. Hidrologia: Ciência e Aplicação. 4. ed. Porto Alegre: Editora: UFRGS; EDUSP e ABRH, 2007.

WANDERLEY, H. S.; AMORIM, R. F. C.; CARVALHO, F. O. Variabilidade Espacial e Preenchimento de Falhas de Dados Pluviométricos para o Estado de Alagoas. Revista Brasileira de Meteorologia, São José dos Campos, v. 27, n. 3, p.347 353, 2012. 